\title{
Factors and Home- and Community-Based Services (HCBS) that Predict Older Adults' Residential Transitions
}

\author{
Ya-Mei Chen ${ }^{1}$, Elaine Adams Thompson², Bobbie Berkowitz ${ }^{3}$, Heather M. Young ${ }^{4}$, Deborah Ward ${ }^{4}$ \\ ${ }^{1}$ National Taiwan University, Taipei, China; ${ }^{2}$ University of Washington, Seattle, USA; ${ }^{3}$ Columbia University, New York, USA; \\ ${ }^{4}$ University of California, Oakland, USA. \\ Email: yameic@u.washington.edu
}

Received February 21 ${ }^{\text {st }}, 2011$; revised April 25 ${ }^{\text {th }}, 2011^{\text {’ }}$ accepted May $16^{\text {th }}, 2011$.

\begin{abstract}
Objectives: This study identified specific personal factors and home- and community-based services (HCBS) that predict older adults' residential transitions between community and institutional settings. Method: Logistic regression of interview data from 5294 participants in the Second Longitudinal Study of Aging identified predictors of three residential transition patterns and of frequency and duration of institutional services use. Results: Different HCBS services differently affected residential transitions. Informal support and paid personal care services (PCS) were the main factors affecting older adults' ability to reside in community settings or to remain in community longer. Frequency of HCBS use and quantity of paid PCS used indicated direction of transitions: from communities into institutions or vice versa. Discussion: Integration of informal and formal care systems and attention to community-dwelling older adults' HCBS use and paid PCS use, as a guide for possible future transitions, are tasks for community care professionals.
\end{abstract}

Keywords: Long-term Care, Policy, Community-based Services, HCBS, Older Adults, Residential Transitions

\section{Introduction}

Research studies that investigate personal factors and home- and community-based services (HCBS) that predict older adults' use of nursing home services make a long list in the PUBMED library, but none takes older adults' residential transitions into consideration. Personal factors and HCBS use patterns that predict older adults' residential transitions could be different from the factors and service patterns that predict nursing home use. As HCBS become increasingly available, older adults transit through different residential statuses over a period of time. Different transition patterns have been noted. As various services meet their needs, older adults may move from communities to institutions or from institutions back to communities. Our aim was to explore which personal factors and which HCBS uses predict different residential transitions. With such knowledge, communities with specific needs can better allocate resources for older adults. This knowledge will be valuable for developing an effective community-based long-term care system.

\section{Background}

Factors that predict older adults' nursing home use have been investigated for decades [1,2]. Many personal factors, such as age, education level, and social support, have been found to be significantly predict older adults' subsequent nursing home use $[3,4]$. Ever since HCBS developed in the 1970s, research studies have further included HCBS to investigate its effect on older adults' nursing home use [3,5-7]. However, findings have been inconsistent. Most studies in the literature reported a positive relationship between older adults' use of HCBS and nursing-home admissions [6,8]. Some showed HCBS to reduce nursing-home admissions only for some groups $[6,9,10]$.

Home and community-based settings refer to houses or units in facilities which provide residents with autonomy and control over living and service arrangements. Residential settings in units that are neither self-contained nor self-sufficient are considered institutions; total care, including skilled nursing care, personal care, and household functions, is provided. Units in institutions are often 
shared by nonrelated residents. Because HCBS are increasingly available, older adults may transit through different residential statuses as the various services meet their needs. However, research studies have failed to acknowledge societal changes in HCBS availability and older adults' residential transitions. This may contribute to the inconsistent and controversial findings in the literature regarding the effect of HCBS on nursing-home use. Bishop (1999) has pointed out the need for better population-based studies to track these residential transitions and ascertain whether older adults with disabilities are receiving the care they need.

Another issue contributing to inconsistent research findings is the cross-sectional design commonly used in previous research studies on aging and the effects older adults' HCBS use, and it does not allow researchers to study the dynamic of older adults' residential transitions and use of HCBS [11]. Investigating HCBS and residential transitions from a longitudinal perspective may provide a better picture of the effects of HCBS. This study used Andersen's Health Behavioral Model to predict older adults' residential transitions in a national longitudinal dataset that covered 6 years of study

\section{Conceptual Framework-Health Behavioral Model (HBM)}

The conceptual framework was based upon Andersen's HBM model, one of the most widely used behavioral models, to encompass older adults' use of HCBS, as well as all the Health Behavioral Model factors, as influences on behavior in the form of residential transitions [12-16]. It posits that older adults' use of HCBS and ability to remain in their communities through different residential transitions is a function of 1) their predisposition to use services; 2) factors that enable or impede their use of services; and 3) their perceived need for services and older adults ability to remain in community is the function of the three factors mentioned above plus older adults' use of HCBS.

\subsection{Predisposing Factors}

The model's predisposition component describes the ways in which some individuals have a greater propensity to use health services than do others. Such propensities can be predicted based on certain characteristics of the individual, such as age and gender, prior to the onset of any specific illness episode [3,13,17]. These characteristics have been reported to affect older adults' HCBS use $[15,16]$ and older adults' nursing home use [18,19].

\subsection{Enabling Factors}

A condition that permits an individual to act on a value or to satisfy a need is defined as an enabling condition.
Enabling conditions include the social environment, such as informal caregiving support and home environment, and financial resources, such as family income status [13]. Miller and Weissert's review [18] showed receipt of informal caregiving associated with increased risk of institutionalization.

\subsection{Perceived Need Factors and Disability Factors}

Finally, although predisposing and enabling factors are necessary conditions for the use of health services, they are not sufficient. To seek services, an individual must perceive some need to do so. Apart from age, need factors have the greatest impact on nursing home entry [20]. Perceived need may result from illness or from aging-related functional disabilities. Researchers have found perceived need for services to be important for HCBS use among families providing care to dependent older adults [16]. Awareness of needs allows appropriate matching of services HCBS to enable individuals to live independently for as long as possible [21]. Disability factors are also key factors for HCBS use and for older adults' ability to live in communities [4,16,22,23].

\subsection{HCBS Use}

Since older adults are likely to use community-based services before turning to institutional services, we also expected older adults' use of HCBS to be an important factor in their residential transitions. Our conceptual framework focuses on the relationship between older adults' use of HCBS and their ability to remain in communities through different kinds of transitions. Discussions about this relationship vary. Some studies report that disabled older persons who received formal HCBS services entered nursing homes at a higher rate [8,24]; other studies report the opposite relationship and conclude that, when targeted to an appropriate subgroup, use of nondiscretionary services is negatively associated with nursing home use [6,10]. However, it has been unclear whether different HCBS predicted different transitions.

The purpose of this study was: 1) To identify factors related to older adults' personal characteristics, such as age and gender, that predict older adults' residential transitions, and 2) To identify uses of HCBS that predict older adults' residential transitions, such as identifying what services might help older adults remain in their communities longer, and what services might help them move back to their communities after having been institutionalized. This study used the Health Behavioral Model as a framework and guide for selecting variables and for analyzing the relationships between older adults' use of HCBS and their 
residential transitions with a longitudinal perspective.

\section{Methods}

\subsection{Data Source-The Second Longitudinal Study of Aging (LSOA II)}

The study used data from the Second Longitudinal Study of Aging (The Second Longitudinal Study of Aging, 2002). Using the LSOA II, this study analyzed nationally representative civilian noninstitutionalized persons aged 70 years or older. Sampling followed a stratified, multistage probability design that permitted continuous sampling of the target population. After baseline face-to face interviews in 1994 (Time 1 [T1]; $\mathrm{N}=9447$ ), two followup interviews occurred using Computer Assisted Telephone Interviews [25]: one between 1997 and 1998 (Time 2 [T2]; $\mathrm{N}=7,060$ ), and one between 1999 and 2000 (Time 3 [T3]; $N=5,294$ ). Loss of respondents was due to attrition from death and loss of tracking. Our analysis included only those respondents who participated in all three waves $(\mathrm{N}=5,294)$. Three sample weights were employed to account for the LSOA II complex sampling survey design.

Missing values in the study variables represented less than $5 \%$ of observations, with the exception of the community service utilization variables (missing $8.8 \%$ to $15.6 \%$ of observations) and the income variable (missing $21 \%$ of observations). We replaced missing values from responses such as "not ascertained" and "don't know or refused" using the Markov Chain Monte Carlo method through the multiple-imputation procedure in LISREL 8.53 [26].

\subsection{Sample}

A total of 5294 older adults, those who had completed all three LSOA II interviews, were included in the data analysis for this study. At baseline interview in 1994, respondents' ages ranged from 70 to 99 years, with a mean of $75.52 \pm 5.26$. About two thirds of the respondents (63.1\%) were female. Participants' average number of years of education was $11.46 \pm 3.40$. Family income ranged from $\$ 1,000$ to more than $\$ 50,000$ a year, with an average range of $\$ 15,000$ to $\$ 16,999$. The participants were living alone (33.8\%) or with a spouse or other family member (65.4\%) (Please see Table 1).

\subsection{Measures}

Variables for this study were selected based on the Health Behavioral Model described above. The dependent variables were older adults' residential transitions; the independent variables were older adults' use of HCBS. Older adults' personal factors, based on the Health Behavioral Model variables, were included as covariates.

\subsubsection{Dependent Variables—Older Adults' Residential Transitions}

At each interview (T1, T2, and T3), each older adult was either in a home- and community-based setting (C) or in an institution (I). Home- and community-based settings included 1) single-family homes; 2) regular apartments; 3) retirement homes; 4) assisted living facilities; 5) supervised apartments; 6) group homes; 7) halfway houses; 8) board homes; and 9) developmental centers. Institutions included 1) nursing homes and 2) convalescent homes. All older adults included in LSAO II lived in communities at T1 interview. The question asked at T2 and T3 interviews regarding older adults' residential status was: "Is the place where you live a $\cdots$ (one of the 11 options described above)?" and "Since the last interview, have you been a resident in a nursing home/convalescent home?” (The Second Longitudinal Study of Aging-The Second Supplement on Aging, 1994). Each respondent who indicated living in a nursing home, in answers to either of these questions, was considered a transition to institution during that period of time. Respondents whose answers did not indicate nursing home use were considered to be living in community. When respondents moved between living arrangements, the transitions were noted. Data in LSOA II were collected three times: in 1994 (T1), 1997 (T2), and 2000 (T3). Using these three time points, we defined four types of residential transitions: 1) CCC: older adults who resided in community from T1 to T3 and did not use any nursing home service from 1994 to 2000; 2) CIC: older adults who resided in community at $\mathrm{T} 1$, had moved to an institution between T1 and T2, including T2, and had returned to community and had not used any nursing home services between T2 and T3; 3) CCI: older adults who resided in community between T1 and T2, including T2, and did not use any nursing home services during this period of time, but had used nursing home services between T2 and T3, including at T3; and 4) CII: older adults who resided in community at $\mathrm{T} 1$ but resided in an institution between $\mathrm{T} 1$ and $\mathrm{T} 2$, including $\mathrm{T} 2$, and between $\mathrm{T} 2$ and $\mathrm{T} 3$, including at T3.

\subsubsection{Independent Variables-Older Adults' HCBS Use}

A total of 13 HCBS were available in the LSOA II between T1 and T2 interviews, as well as the frequency of services use during the three months prior to the T2 interview. These services were 1 ) senior centers; 2) meals On Wheels; 3) meals at senior centers/facilities; 4) homemaker/companion services; 5) personal care services (PCS); 6) skilled nursing care; 7) physical therapy; 8) occupational therapy; 9) speech therapy; 10) dialysis; 11) tube feeding; 12) oxygen or respiratory therapy, and 
Table 1. Definition and distribution of health behavioral model (HBM) covariates (data from T1 interview).

\begin{tabular}{|c|c|c|}
\hline HBM Variables & Operational Definitions & Mean (SD, Range) \\
\hline \multicolumn{3}{|c|}{ Predisposing Factors } \\
\hline Age & Years of age & $75.52(5.26,69-97)$ \\
\hline Education & Years of education & $11.46(3.41,0-18)$ \\
\hline Household size & No. living in the same household & $1.85(0.91,1-11)$ \\
\hline Condor & Female & $\mathrm{N}=3339(63.07 \%)$ \\
\hline Gender & Male & $\mathrm{N}=1955(36.93 \%)$ \\
\hline Marital status & Married & $\mathrm{N}=2928(55.42 \%)$ \\
\hline \multicolumn{3}{|c|}{ Enabling Factors } \\
\hline Unpaid ADL help & $\begin{array}{l}\text { Types of Activities of Daily Living (e.g., bathing) assisted by up } \\
\text { to four unpaid helpers }(0-28)\end{array}$ & $0.24(1.13,0-18)$ \\
\hline Unpaid IADL help & $\begin{array}{l}\text { Types of Instrumental Activities of Daily Living (e.g., preparing } \\
\text { a meal) assisted by up to four unpaid helpers ( } 0 \text { - 32) }\end{array}$ & $0.68(1.91,0$ - 27) \\
\hline Unpaid help hour & $\begin{array}{l}\text { Hours of unpaid help received in the } 2 \text { weeks prior to } \mathrm{T} 1 \text { inter- } \\
\text { view by up to four unpaid helpers }(0-1334)\end{array}$ & $7.64(40.57,0$ - 684) \\
\hline Medicare & Covered by Medicare (yes/no) & $\mathrm{N}=5282(99.8 \%)$ \\
\hline Medicaid & Covered by Medicaid (yes/no) & $\mathrm{N}=418(7.95 \%)$ \\
\hline Private insurance & Covered by private insurance (yes/no) & $\mathrm{N}=4189(79.13 \%)$ \\
\hline Family income & $\begin{array}{l}\text { Higher scores indicate higher income }(0=\text { less than } \$ 1,000 ; 26= \\
\$ 50,000+)\end{array}$ & $17.12(6.58,0-26)$ \\
\hline \multicolumn{3}{|c|}{ Disability Factors } \\
\hline Functional limitations & $\begin{array}{l}\text { No. of functional activities (e.g., climbing stairs, bending, lift- } \\
\text { ing) unable to perform }{ }^{\mathrm{a}}(0-10)\end{array}$ & $1.95(2.47,0-10)$ \\
\hline ADL disabilities & No. of ADLs unable to perform ${ }^{\mathrm{b}}(0-7)$ & $0.55(1.31,0-7)$ \\
\hline IADL disabilities & No. of IADLs unable to perform ${ }^{\mathrm{c}}(0-8)$ & $0.62(1.41,0-8)$ \\
\hline Housing difficulties & $\begin{array}{l}\text { No. of difficulties entering or leaving home, opening or closing } \\
\text { doors, reaching or opening cabinets, using bathroom }(0-4)\end{array}$ & $0.21(0.94,0-4)$ \\
\hline Unmet need in ADL (0 - 7) & $\begin{array}{l}\text { Number of ADLs needed more assistance, regardless of whether } \\
\text { received support for such activities }\end{array}$ & $0.06(0.431,0-7)$ \\
\hline Unmet need in IADL (0 - 8) & $\begin{array}{l}\text { Number of IADLs needed more assistance in IADL, regardless } \\
\text { of whether received support for such activities. }\end{array}$ & $0.08(0.452,0-6)$ \\
\hline
\end{tabular}

Note: all data from The Second Longitudinal Study of Aging-The Second Supplement on Aging: 1994 (Version 2, No. 1, September 1998) [Data file]. Hyattsville, MD: National Center for Health Statistics. Available from http://www.cdc.gov/nchs/about/otheract/aging/lsoa2.htm. ${ }^{\mathrm{a}}$ From "An epidemiology of disability among adults in the United States,” by Nagi, 1976, Milbank Memorial Fund Quarterly, Vol. 54, No. 4, pp. 439-476. 'From “Index of ADL,” by Katz and Akpom, 1976, Medical Care, pp. 116-118. 'From “Assessment of older people; self-maintaining and instrumental activities of daily living,” by Lawton and Brody, 1969, The Gerontologist, Vol. 9, pp. 179-186.

13) Hospice care. HCBS include two types of services, based on service characteristics: nondiscretionary and discretionary. Discretionary services are health services used primarily by individual choice. Homemaker or personal care services (PCS) are examples of discretionary HCBS. In contrast, nondiscretionary HCBS are health services such as skilled nursing care that are used primarily on health care providers' orders or suggestions [14]. Failure to differentiate among services based upon the degree to which they were discretionary might be the reason researchers have generally found need for services to be the most significant predictor of service use [14]. For the purpose of this study, the first five services described in the paragraph above were considered discre- tionary services; all the other services were considered nondiscretionary services. Except for senior centers and meals at senior center/facility, all of these services were received in the home. Although paid PCS were initially considered discretionary services, older adults who received these services were less likely to use other types of discretionary services [16,22,27]. Therefore, it is reasonable to assume that paid PCS are qualitatively different from other discretionary services and should be examined in different categories [28].

The question asked at T2 interview for the first 3 community services was, "In the past 12 months, did you go to/use ‥ (the services)?” [29] For the 10 in-home services, the questions asked were, "Since (month/year of 
last interview) did you receive any health care services IN YOUR HOME? This would include skilled nursing care, physical or occupational therapy, assistance with medications or personal care needs, and any other services provided IN YOUR HOME by a visiting nurse, nursing assistant, home health aide, personal assistant, therapist, or homemaker" and "Which of the following services did you receive? Did you receive (01) Skilled nursing care (02) Physical therapy (03) Occupational therapy (04) Speech therapy (05) Dialysis (06) Tube feeding (07) Personal assistant services (08) Homemaker/companion services (09) Oxygen/respiratory therapy (10) Hospice care" [29]. The question asked at T2 interview regarding frequency of service use was, "What was the total number of times you received any of these services in the past 3 months?” [29]. Information about paid PCS services was obtained from respondents' descriptions, at T2 interview, of their four main caregivers who provided ADL or IADL support. Where respondents indicated that caregivers were paid, data were included for analysis. In addition to paid PCS, information regarding other services used data from the T2 interview data. All these service use between T1 and T2, including at T2. Figure 1 shows residence and service use from T1 interview to $\mathrm{T} 3$ interview.

As a result, five variables were used to assess older adults' use of HCBS between T1 and T2: (1) the number of types of discretionary services used between the T1 and T2 interviews, (2) the number of types of nondiscretionary services used between the $\mathrm{T} 1$ and $\mathrm{T} 2$ interviews, (3) the total number of times HCBS used in the three months prior to the T2 interview, (4) number of types of paid ADL PCS received, and (5) number of types of paid IADL PCS received. Table 1 provides detailed descriptions of the HCBS-use variables and their distribution in the sample population. About $40.4 \%$ of the sample re- ceived HCBS between T1 and T2 (Table 2).

\subsubsection{Covariates-Health Behavioral Model Factors}

The covariates included in this study were based on Anderson's Health Behavioral Model (HBM). HBM posits that people's use of health services and residential transitions is a function of their predisposition to use services, such as age and gender; the factors that enable or impede their use of services, such as family income and the number of types of unpaid help from friends and family; and their personal need for care, such as number of difficulties with functional activities, Activities of Daily Living, and Instrumental Activities of Daily Living (Please see Table 1 for detailed descriptions of variables included in these factors).

\subsection{Analysis}

Multiple logistic regression procedures were used to identify predictors for different residential transitions. The selected variables were consistent with literature findings. Predisposing factors, enabling factors, disability factors, and older adults' use of HCBS as described in previous sections were used to predict four residential transitions:

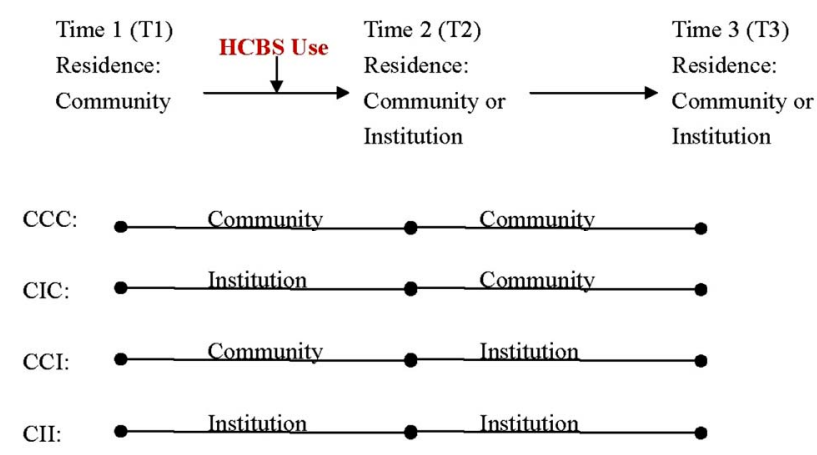

Figure 1. Older adults' HCBS use and residential from time 1 to time 3.

Table 2. Definition and distribution of home- and community-based services (HCBS) variables (data from T2 interview).

\begin{tabular}{|c|c|c|}
\hline HCBS Variables & Operational Definitions & Mean (SD, Range) \\
\hline Nondiscretionary services & Number of types nondiscretionary services $(0-8)$ & $0.22(0.62,0-6)$ \\
\hline Discretionary services & Number of types of discretionary services $(0-4)$ & $0.47(0.77,0-4)$ \\
\hline \multicolumn{3}{|l|}{ Personal care services (PCS) } \\
\hline Paid ADL PCS & $\begin{array}{l}\text { Types of ADL assistance received from up to four paid personal } \\
\text { care services }(0-28)\end{array}$ & $0.24(1.13,0-18)$ \\
\hline Paid IADL PCS & $\begin{array}{l}\text { Types of IADL assistance received from up to four paid personal } \\
\text { care services }(0-32)\end{array}$ & $0.68(1.91,0-27)$ \\
\hline Paid PCS days & $\begin{array}{c}\text { Days of paid PCS received in the } 2 \text { weeks prior to T2 interview } \\
\text { by up to four paid helpers () }\end{array}$ & \\
\hline Frequency of HCBS use & $\begin{array}{c}\text { Total number of times HCBS used in the } 3 \text { months prior to } \mathrm{T} 2 \\
\text { interview }\end{array}$ & $2.02(9.84,0$ - 99) \\
\hline
\end{tabular}

Note: all data from The Second Longitudinal Study of Aging-Wave 2 Survivor Data File (Version SF1.2, June 2002) [Data file]. Hyattsville, MD: National Center for Health Statistics. Available from http://www.cdc.gov/nchs/about/otheract/aging/lsoa2.htm. 
1) CCC; 2) CIC; 3) CCI; and 4) CII. Odds ratios and pseudo- $R^{2}$ were reported. The level of significance was set at $p \leq 0.05$. STATA 9.0 survey suite was used for statistical analysis to address the complex sample design used in LSOA II.

\section{Results}

Among the 5294 older adults included in the current study, there were 4649 (87.8\%), 92 (1.7\%), 384 (7.3\%),

Table 3. Descriptive results of older adults in the four residential transition groups.

\begin{tabular}{|c|c|c|c|c|}
\hline \multirow[b]{2}{*}{ Predisposing Factors } & \multicolumn{4}{|c|}{$\begin{array}{c}\text { Residential Transition Groups } \\
\text { (Mean/Percentage) }\end{array}$} \\
\hline & CCC & CIC & CCI & CII \\
\hline Age & 75.07 & 77.86 & 78.28 & 80.22 \\
\hline Education & 11.55 & 11.22 & 11.06 & 10.12 \\
\hline Size of family & 1.87 & 1.89 & 1.70 & 1.63 \\
\hline Gender (Female \%) & $61.6 \%$ & $71.7 \%$ & $71.1 \%$ & $81.7 \%$ \\
\hline Marital status (Married \%) & $57.5 \%$ & $45.7 \%$ & $41.2 \%$ & $42.0 \%$ \\
\hline \multicolumn{5}{|c|}{ Enabling Factors (Data from T1 Interview) } \\
\hline Unpaid ADL help (0 - 28) & 0.19 & 0.72 & 0.33 & 1.27 \\
\hline Unpaid IADL help (0 - 32) & 0.55 & 1.61 & 1.16 & 2.71 \\
\hline Unpaid help hour (0 - 708) & 6.26 & 15.85 & 12.08 & 34.88 \\
\hline House modification & 1.03 & 1.40 & 1.42 & 1.88 \\
\hline \multicolumn{5}{|c|}{ Financial Enabling Factors (From T1 Interview) } \\
\hline Medicaid (yes) & $97.2 \%$ & $98.9 \%$ & $97.4 \%$ & $94.7 \%$ \\
\hline Medicaid (yes) & $7.6 \%$ & $6.7 \%$ & $8.9 \%$ & $14.8 \%$ \\
\hline Private insurance (yes/no) & $80.5 \%$ & $81.8 \%$ & $75 \%$ & $64.5 \%$ \\
\hline Family income & 17.37 & 16.90 & 15.62 & 13.54 \\
\hline \multicolumn{5}{|c|}{ Disability Factors (Data from T1 Interview) } \\
\hline Nagi's function limitation $(0$ - 10) & 1.79 & 3.25 & 2.74 & 4.15 \\
\hline ADL disability $(0-7))$ & 0.46 & 1.23 & 0.91 & 1.95 \\
\hline IADL disability (0 - 8) & 0.51 & 1.29 & 1.08 & 2.26 \\
\hline Difficulty with elders' house (0 - 4) & 0.17 & 0.53 & 0.27 & 0.73 \\
\hline Unmet need in ADL (0 - 7) & 0.04 & 0.02 & 0.13 & 0.29 \\
\hline Unmet need in IADL (0 - 8) & 0.07 & 0.07 & 0.14 & 0.30 \\
\hline \multicolumn{5}{|c|}{ HCBS (Data From T2 Interview) } \\
\hline Nondiscretionary services $(0-8)$ & 0.18 & 1.08 & 0.40 & 0.93 \\
\hline Discretionary services (0 - 4) & 0.44 & 0.98 & 0.71 & 1.11 \\
\hline HCBS frequency & 1.42 & 10.11 & 6.35 & 12.08 \\
\hline Paid ADL PCS (0 - 28) & 0.05 & 0.45 & 0.40 & 0.52 \\
\hline Paid IADL PCS (0 - 32) & 0.16 & 0.59 & 0.47 & 0.47 \\
\hline Paid PCS days & 0.11 & 0.33 & 0.31 & 0.30 \\
\hline
\end{tabular}

Note 1: all data from The Second Longitudinal Study of Aging-The Second Supplement on Aging: 1994 (Version 2, No. 1, September 1998); Wave 2 Survivor Data File (Version SF1.2, June 2002); Wave 3 Survivor Data File (Version SF2.1, October 2002) [Data file]. Hyattsville, MD: National Center for Health Statistics. Available from http://www.cdc.gov/nchs/about/otheract/aging/lsoa2.htm. Note 2: Community $(C)$ : Home- and community-based settings are settings either in a housing unit or in a facility which provides residents with autonomy and control over their living and service arrangements. Institution (I): Residential settings in units that are neither self-contained nor self-sufficient are considered institutions and units in such settings are often shared by nonrelated residents (including settings like nursing homes and convalescent or rest homes). and 169 (3.2\%) in CCC, CIC, CCI, and CII groups respectively. Older adults in CCC group were generally younger, having higher education level, bigger family size, and better financial status than older adults in other groups. Older adults in this group also had less physical disabilities and used less HCBS than older adults in other groups. Table 3 provides detailed descriptive information about older adults in the four groups.

\subsection{Factors Predicting Different Residential Transitions}

Odds ratios generated from a series of logistic regression analysis were reported. Please see Table $\mathbf{4}$ for details.

\subsubsection{CCC}

Older adults' probabilities of remaining in community residences from T1 to T3 declined with increases in age $(p<0.001)$, and number of types of nondiscretionary $(p$ $<0.001)$ and discretionary services $(p<0.001)$ used. Older adults' probabilities of remaining in the community from T1 to T3 increased with Medicaid coverage ( $p<$ $0.05)$ and private insurance coverage $(p<0.05)$. The pseudo- $R^{2}$ was 0.15 .

\subsubsection{CIC}

The probabilities of older adults who had been living in communities at $\mathrm{T} 1$ returning to communities between $\mathrm{T} 2$ and T3 after being in an institution between T1 and T2 declined with Medicaid coverage $(p<0.01)$ and with increases in HCBS use frequency $(p<0.05)$ and hours of help from unpaid caregivers $(p<0.01)$. Older adults' probabilities of this residential transition pattern increased with increase in age $(p<0.05)$, number of types of unpaid ADL help received ( $p<0.05$ ), number of types of nondiscretionary services $(p<0.001)$ and discretionary services used $(p<0.05)$, and number of paid IADL PCS used $(p<0.05)$ used. The pseudo- $R^{2}$ was 0.09 .

\subsubsection{CCI}

Older adults' probabilities of living in their communities between $\mathrm{T} 1$ and $\mathrm{T} 2$ but in an institution between $\mathrm{T} 2$ and $\mathrm{T} 3$ declined with increase in number of difficulty with the house that older adults were living $(p<0.01)$. Older adults' probabilities of this residential transition increased with increase in age $(p<0.001)$, number of ADLs the sample person perceived needing more help $(p<$ 0.01 ), number of types of discretionary services used ( $p<$ $0.05)$, and frequency of HCBS use $(p<0.01)$. The pseudo- $R^{2}$ was 0.06 .

\subsubsection{CII}

Older adults' probabilities of being in CII group, who lived in their communities at $\mathrm{T} 1$ but were admitted to a nursing home at least once between T1 to T2 as well as between $\mathrm{T} 2$ to $\mathrm{T} 3$, declined with private insurance cov- 
erage $(p<0.01)$. Older adults' probabilities of this residential transition increased with increases in age $(p<$ 0.001 ), and number of types of nondiscretionary $(p<$ $0.001)$ and discretionary services $(p<0.05)$ used. The pseudo- $R^{2}$ was 0.12 .

\subsection{Summary}

Older adults who were younger, had Medicaid and private insurance coverage, and used less types of both discretionary and nondiscretionary services were more likely to continue living in communities over the 6 years of the study period. Older adults who were older, had received more types of unpaid ADL help but less total unpaid hours from unpaid caregivers, and did not have
Medicaid coverage were more likely to move into an institution at least temporarily, with the possibility of returning to the community increasing if they used more types of nondiscretionary and discretionary services, used these services infrequently, and purchased more paid IADL PCS. Older adults who were older, perceived less difficulty with the house they were living in, and had more unmet ADL needs seemed to be able to stay in community longer if they used more types of discretionary services and purchased more days of PCS. However, these services did not necessarily prevent older adults with these factors from having to move into an institution eventually. Older adults who were older, did not have private insurance coverage, and used more types of dis-

Table 4. Odds ratios predicting older adults' residential transitions.

\begin{tabular}{|c|c|c|c|c|c|c|c|c|}
\hline \multirow[b]{3}{*}{$\begin{array}{c}\text { Health Behavioral Model } \\
\text { (HBM) Variables }\end{array}$} & \multicolumn{8}{|c|}{ Residential Transitions } \\
\hline & \multicolumn{2}{|c|}{ CCC } & \multicolumn{2}{|c|}{ CIC } & \multicolumn{2}{|c|}{ CCI } & \multicolumn{2}{|c|}{ CII } \\
\hline & OR & CI & OR & CI & OR & CI & OR & $\mathrm{CI}$ \\
\hline \multicolumn{9}{|l|}{ Predisposing Factors } \\
\hline Age & $0.92^{* * *}$ & $0.90-0.94$ & $1.07^{*}$ & $1.01-1.12$ & $1.07^{* * *}$ & $1.04-1.10$ & $1.10^{* * *}$ & $1.05-1.16$ \\
\hline Education & 1.02 & $0.97-1.07$ & 1.02 & $0.92-1.13$ & 0.98 & $0.93-1.03$ & 0.97 & $0.87-1.07$ \\
\hline Family size & 1.03 & $0.88-1.21$ & 0.94 & $0.63-1.39$ & 0.99 & $0.81-1.22$ & 0.92 & $0.66-1.29$ \\
\hline Gender & 0.83 & $0.64-1.07$ & 1.42 & $0.71-2.84$ & 1.06 & $0.78-1.45$ & 1.43 & $0.77-2.68$ \\
\hline Marital status & 0.89 & $0.65-1.23$ & 1.03 & $0.91-1.16$ & 1.03 & $0.91-1.16$ & 1.12 & $0.91-1.38$ \\
\hline \multicolumn{9}{|l|}{ Enabling Factors } \\
\hline Unpaid ADL help & 0.99 & $0.86-1.13$ & $1.51^{*}$ & $1.06-2.14$ & 0.85 & $0.72-1.01$ & 1.08 & $0.92-1.27$ \\
\hline Unpaid IADL help & 0.91 & $0.81-1.01$ & 1.17 & $0.93-1.47$ & 1.06 & 0.94- 1.19 & 1.12 & $0.98-1.29$ \\
\hline Unpaid help hour & 1.00 & 1.00- 1.01 & $0.98^{* *}$ & $0.97-0.99$ & 1.00 & 0.99- 1.00 & 1.00 & $0.99-1.00$ \\
\hline Medicare & 1.17 & $0.51-2.68$ & 0.88 & $0.11-7.10$ & 1.17 & $0.45-3.03$ & 0.46 & $0.19-1.12$ \\
\hline Medicaid & $2.07^{*}$ & $1.16-3.67$ & $0.05^{* *}$ & $0.01-0.31$ & 0.56 & $0.31-1.03$ & 0.60 & $0.24-1.53$ \\
\hline Private insurance & $1.68^{* *}$ & $1.20-2.35$ & 0.52 & $0.22-1.21$ & 0.81 & $0.54-1.22$ & $0.46^{* *}$ & $0.26-0.81$ \\
\hline Family income & 1.00 & $0.98-1.03$ & 1.02 & $0.96-1.09$ & 1.00 & $0.97-1.03$ & 0.98 & $0.94-1.02$ \\
\hline \multicolumn{9}{|l|}{ Disability Factors } \\
\hline Functional limitations & 1.02 & $0.95-1.10$ & 1.07 & $0.91-1.27$ & 1.02 & $0.94-1.10$ & 0.91 & $0.80-1.03$ \\
\hline ADL disabilities & 0.90 & $0.78-1.03$ & 0.92 & $0.71-1.20$ & 1.12 & $0.93-1.34$ & 1.11 & $0.89-1.39$ \\
\hline IADL disabilities & 0.95 & $0.81-1.12$ & 0.79 & $0.49-1.27$ & 1.08 & $0.91-1.27$ & 1.08 & $0.84-1.38$ \\
\hline Housing difficulties & 1.11 & $0.89-1.40$ & 1.41 & $0.80-2.48$ & $0.66^{* *}$ & $0.49-0.89$ & 1.21 & $0.86-1.71$ \\
\hline Unmet ADL needs & 0.86 & $0.65-1.12$ & 0.51 & $0.18-1.43$ & $1.42^{* *}$ & $1.11-1.83$ & 0.87 & $0.51-1.50$ \\
\hline Unmet IADL needs & 1.07 & $0.82-1.40$ & 0.64 & $0.25-1.64$ & 0.93 & $0.70-1.24$ & 1.08 & $0.70-1.68$ \\
\hline \multicolumn{9}{|l|}{ HCBS Variables } \\
\hline Nondiscretionary services & $0.62^{* * *}$ & $0.53-0.72$ & $2.75^{* * *}$ & $2.12-3.55$ & 0.95 & $0.72-1.27$ & $1.82^{* * *}$ & $1.44-2.30$ \\
\hline Discretionary services & $0.67^{* * *}$ & $0.58-0.79$ & $1.39^{*}$ & $1.03-1.88$ & $1.23^{*}$ & $1.04-1.46$ & $1.67^{*}$ & $1.12-2.48$ \\
\hline \multicolumn{9}{|l|}{ Personal care services } \\
\hline Paid ADL PCS & 0.84 & $0.70-1.01$ & 0.95 & $0.71-1.25$ & 1.13 & $0.97-1.32$ & 1.07 & $0.85-1.34$ \\
\hline Paid IADL PCS & 1.03 & $0.80-1.32$ & $1.28^{*}$ & $1.01-2.06$ & 0.84 & $0.66-1.06$ & 1.00 & $0.75-1.33$ \\
\hline Paid PCS days & 0.70 & $0.46-1.06$ & 0.87 & $0.38-2.01$ & $2.15^{* * *}$ & $1.53-3.03$ & 0.66 & $0.33-1.31$ \\
\hline Frequency of HCBS use & 0.99 & $0.98-1.00$ & $0.96^{*}$ & $0.92-0.99$ & $1.02^{* *}$ & $1.01-1.03$ & 1.00 & $0.99-1.02$ \\
\hline Pseudo- $R^{2}$ & 0.15 & & 0.09 & & 0.06 & & 0.12 & \\
\hline
\end{tabular}

Note: CCC: from community (1994) to community (1998) to community (2000); CIC: from community to institution and back to community; CCI: from community to community to institution; ${ }^{*} p<0.05 .{ }^{* *} p<0.01 .{ }^{* *} p<0.001$; a. Paid ADL help was dropped from analysis in the CIC group due to too little cases and variation in older adults' responses. 
cretionary and nondiscretionary services were more likely to demonstrate a CII transition pattern, which indicated more frequent or even long term use of institutional services. Table 4 summarizes the predictors of older adults' residential transitions.

\section{Discussion}

This study contributes to health services research by examining which older adults' personal factors and HCBS use predict their residential transitions. The CCC transition revealed factors supporting older adults to continue staying in communities. The CIC transitions generated information about what factors contribute to older adults moving back to their communities after having been institutionalized. The CCI transitions provided information about what factors contribute to older adults remaining in their communities longer before needing an institution. The fourth type of transition, CII, indicated factors that resulted in older adults' frequent or long-term use of institutional services. Past research focused on knowing whether services predicted nursing-home admissions, yet understanding the various ways HCBS affect residential transitions for older adults with different characteristics will be even more important for policy makers.

Our study findings pointed to predictors of different transitions, providing the first evidence showing differential impacts of different older adults' personal factors and different HCBS use on older adults' residential transitions. Different types and frequency of HCBS use predicted different patterns of residential transitions. In addition to validating Jette and colleagues' suggestion that future research should examine the impact of specific types of community care and provide further information about the possible different effects of different HCBS [6], our findings, also pointed out the importance of considering older adults' residential transitions when studying the effects of HCBS. The following discussion integrates and compares the findings to provide a broader picture of the ways these factors influence older adults' residential transitions.

\subsection{Older Adults' Personal Factors and Their Residential Transitions}

Findings regarding older adults' personal factors echoes literature findings that being older is more likely to positively predict their transition to nursing home $[6,8,30]$. However, several factors identified in the literature that predicted older adults' nursing home admission did not significantly predict older adults' different residential transitions, such as income and physical disabilities [3]. These findings showed that older adults' personal factors predicting older adults' residential transitions are differ- ent from the factors predicting nursing home use.

The literature has reported having more informal support to be both associated with and not associated with increased risk of nursing home admission [1,18,31]. Our study findings provided further explanation: that lack of informal support could predict older adults' nursinghome admission, but not older adults' residential transitions. It is possible that the effect of informal support was attenuated when all types of nursing-home use were combined. Our findings indicated that having such support seemed to enable older adults to return to communities after being institutionalized. In the current study, older adults who had more types of help for ADL disabilities from unpaid caregivers were more likely to return to community, even after being admitted to an institution, as did the older adults in the CIC group. Although having such informal support could be associated with the use of institutional services, older adults' use of institutional services could just be temporary.

However, our study findings also indicated the importance of not relying on the total amount of informal care, as even using different types of ADL informal support appeared to be a beneficial factor for older adults to return to communities. It is possible that having informal support, but not becoming too dependent on the amount of informal support, is a key for older adults to return to communities after being institutionalized. Policy makers are seeking factors that will enable older adults to return to communities [2]. Our study findings provide information that will help community care professionals better identify the characteristics of older adults who have the potential to return to and remain in communities after being institutionalized.

Our study findings regarding insurance coverage contradicted the literature findings that Medicaid coverage was associated with higher risk of nursing-home placement [18]. In the current study, our findings indicated that having Medicaid coverage seems to be a factor that supports older adults to remain in community settings. Older adults with Medicaid and private insurance coverage were more likely to be in the CCC transition group, which continued living in communities over the 6 years of the study period. Older adults who did not have Medicaid coverage had a higher probability of being in the CIC group, whose members were also admitted to a nursing home, at least temporarily.

This finding may be attributable to the effort and accomplishment of Medicaid HCBS waivers. Miller and colleagues' study (2000) analyzed data collected between 1985 and 1998, when HCBS services were only starting to be developed. Our study used data from 1994 to 2000, which allowed time to see the effects of HCBS and especially of Medicaid HCBS waivers, which passed in 1995. 
A recent systematic review study also reported Medicaid coverage as a factor preventing older adults from nursing home admission [3]. Chen's study (2004) revealed that being covered by Medicaid was significantly predictive of discretionary services use. This finding reflects the Medicaid HCBS waivers implemented in 1995 and shows that the HCBS waivers encouraged the use of discretionary services use by elders and, therefore, provided older adults with Medicaid coverage with higher probabilities to be in communities [32]. In the current study, we further found that having Medicaid coverage plus private insurance seemed to provide older adults with extra support to stay in communities, as were CCC group. Older adults who did not have private insurance coverage were more likely to be in CII group.

\subsection{HCBS and Older Adults' Residential Transitions}

Findings from the four groups of older adults provided potential explanations for the inconsistent findings in the literature regarding the effect of HCBS use among older adults, and the types of HCBS that may assist older adults with different characteristics to achieve different residential transitions. Findings from the CCC and CII groups were consistent with literature findings in that HCBS use is likely to positively predict transition to a nursing home $[8,24]$. However, findings from the CIC and CCI groups showed different messages. Findings from these two groups may provide further information on how HCBS influences nursing-home use for particular groups and reveal information regarding which HCBS might support older adults with specific characteristics to return to communities after institutionalization or to stay in communities longer. (Eng, Pedulla, Eleazer, McCann, \& Fox, 1997; Jette et al., 1995; G. Mitchell, 2nd, Salmon, Polivka, \& Soberon-Ferrer, 2006).

The key for older adults' ability to return to community may be wide-ranging use of HCBS without reliance on the total amount of services. The older adults in the CIC group used HCBS infrequently, yet they used more types of discretionary and nondiscretionary services than did adults in the other groups, and purchased more paid IADL PCS. This pattern may indicate use of services as a functional bridge to support a transition back to living in community.

The effect of using HCBS frequently together with using more types of discretionary services may be to enable older adults to remain in communities longer before what seems to be inevitable nursing-home admission in the future. Older adults in the CCI group used more types of discretionary services, but needed to use HCBS frequently and to purchase more paid PCS days. This pattern of services use indicates greater dependence on the amount of these services, and therefore greater likelihood of moving into more-dependent housing, such as a skilled nursing home, at a later time.

Paid PCS stands out as an important service for enabling older adults to move back into community from an institution, or to remain in community longer before being admitted to an institution. The CII group of older adults, who became more frequent or long-term users of institutions, used HCBS but did not purchase paid PCS. Chen and colleagues (2010) used structural modeling to test a HCBS model and also reported that using paid IADL PCS significantly supported older adults to remain in communities. The current study further revealed that paid PCS helped older adults to remain in communities through two types of residential transitions, CIC and CCI. However, the effects of purchasing paid PCS are conditional to the presence of other key factors, such as informal support. Older adults in the CIC group received informal support for ADL disabilities and formal support for IADL disabilities. This seemed an effective strategy for supporting older adults to return to communities. Without informal support, older adults might be more likely to transit from communities to institution, as did the CCI group discussed earlier. A policy research study reported that in the United States, HCBS effects were conditional on older adults having a child available to provide support [33]. This supports our study findings, which indicated that HCBS would generate greater effects for older adults who had unpaid or informal helpers available.

Older adults in the CCI group, unlike those in the CIC group, did not have significant support from unpaid helpers. To meet their needs, they had to rely entirely on formal services, and they used these services in larger amounts. Yet using formal services, even in large amounts, seemed insufficient to older adults' needs. Older adults in the CCI group perceived higher unmet need, which could result in subsequent nursing-home use after managing to remain in communities for a longer time.

The amount of paid PCS used provided information for predicting older adults' future transitions. Using more types of paid PCS, but in small amounts, would enable older adults to return to communities after being institutionalized (CIC). Increased need for quantity of paid PCS would indicate nursing-home services might be needed in the near future (CCI). Frequency of HCBS use is another key for predicting older adults' transitions. Older adults in the CIC group used HCBS infrequently, while older adults in the CCI group used HCBS more frequently.

In summary, HCBS may not be sufficient to keep older adults in communities, but could support older adults to return to communities or remain in communities longer. Infrequent use of HCBS together with paid IADL 
PCS could be effective in supporting older adults to return to communities, especially for those older adults with better informal support systems. Discretionary services and paid PCS could be more effective for supporting older adults without informal support to remain in communities longer. These older adults may rely on a greater quantity of HCBS and paid PCS. When perceived unmet needs increase, institution admission seems inevitable. Among older adults, higher frequency of HCBS use or greater amount of paid PCS used could be indicators of needing more intensive care.

\subsection{Policy Implications}

The take-home message from these findings is to integrate informal and formal care systems and to pay attention to the frequency of community-dwelling older adults' HCBS use and the amount of their paid PCS use, as a guide for possible future transitions. Mor and colleagues (2007) reported that between $4 \%$ and $12 \%$ of the 1.4 million long-stay nursing-home residents, and similar proportions of new admissions, could live in communities rather than in the nursing homes they live in now. However, transferring these older adults back to community will require well-developed community-based alternative care systems. Findings from the current study provide valuable insights for policy makers and suggest that if governments intend to help older adults transfer back to their communities, the priority services to develop and make available are HCBS services and paid IADL PCS. In the meantime, governments should train community care professionals to pay attention to older adults' frequency of HCBS use and quantity of paid PCS use. Community care professionals could suggest that older adults known to use HCBS frequently or to use large amounts of paid PCS move to more-dependent housing, at least temporarily. On-time referrals could both help older adults and decrease potentially unnecessary use of HCBS in communities. However, the benchmarks of using HCBS "frequently" and of using paid PCS in "large amounts" merit further investigation.

\section{Limitations}

The sample included in this study was less disabled than the overall population included in LSOA II. LSOA II respondents who did not participate in $\mathrm{T} 2$ and $\mathrm{T} 3$ surveys due to death were not included in this analysis; these were the older adults likely to be more disabled. Therefore, the current study's findings may be generalizable only to less disabled older adults, and promoting paid PCS may be a suitable strategy only when targeting the less disabled older adults in communities. Future studies should consider Heckman's (1979) two-stage method to correct the potential sampling bias.
Another limitation is that the data for the older adults in the CIC group could not specify whether their use of HCBS occurred before or after their use of nursing home services. With further analysis of a small subgroup $(\mathrm{N}=$ 20) of older adults who had used HCBS services before institutionalization and were later able to return to community, we found factors similar to the factors found predicting the CIC transition in the current study, such as age, Medicaid coverage, unpaid IADL help, and less frequent use of HCBS. However, a further study to examine the timeline of older adults' HCBS use and institutionalization, using a different database, is merited.

\section{Conclusions}

Previous study findings regarding the effects of HCBS on institution use were unclear and inconsistent [5,6,34]. Our findings provide an explanation that addresses the way HCBS influences older adults' residential transitions as well as the magnitude of the effect of appropriately targeted HCBS use. The findings from the current study also support Greene, Lovely, and Ondrich's (1993) conclusion that appropriate targeting of HCBS would to some degree reduce institution use and expenditures; the service important to target is PCS support.

As baby boomers enter retirement, needs for long-term care for older adults will increase dramatically. It is clear that neither formal services nor informal care can meet the needs of this growing population. Long-term care financing and policy should reflect the capacity of the system to serve older adults in communities. It is therefore pertinent to reconceptualize the linkages between HCBS and institutional services, and between formal service use and informal care, based upon older adults' characteristics, and then to move toward an integrative model.

The residential transition variables included in the current study allow us to describe not only factors that support older adults' ability to remain in communities, but also factors that support older adults' ability to return to communities from institutions, or to remain in communities longer before entering an institution. These findings could inform future policy making and development of better public and private financing strategies for HCBS. Studies have already shown that HCBS cost less than institutional care [35]. Knowing what services best support older adults in different circumstances might further our ability to control costs

\section{REFERENCES}

[1] R. J. Hanley, et al., "Predicting Elderly Nursing Home Admissions. Results from the 1982-1984 National LongTerm Care Survey,” Research on Aging, Vol. 12, No. 2, 1990, pp. 199-228. doi:10.1177/0164027590122004 
[2] V. Mor, et al., "Prospects for Transferring Nursing Home Residents to the Community," Health Affairs, Vol. 26, No. 6, 2007, pp. 1762-1771. doi:10.1377/hlthaff.26.6.1762

[3] J. E. Gaugler, et al., Predicting Nursing Home Admission in the US: A Meta-Analysis," BMC Geriatrics, Vol. 7, 2007, p. 13. doi:10.1186/1471-2318-7-13

[4] A. B. Akamigbo and F. D. Wolinsky, "Reported Expectations for Nursing Home Placement among Older Adults and Their Role as Risk Factors for Nursing Home Admissions,” The Gerontologist, Vol. 46, No. 4, 2006, pp. 464- 473. doi:10.1093/geront/46.4.464

[5] V. L. Greene, et al., "Reducing Nursing Home Use through Community Long-Term Care: An Optimization Analysis,” The Journal of Gerontology: Series B, 1995, Vol. 50, No. 4, pp. S259-S268. doi:10.1093/geronb/50B.4.S259

[6] A. M. Jette, S. Tennstedt and S. Crawford, "How does Formal and Informal Community Care Affect Nursing Home Use?” The Journals of Gerontology: Series B, Vol. 50, No. 1, 1995, pp. S4-S12. doi:10.1093/geronb/50B.1.S4

[7] L. R. Fischer, et al., "Community-Based Care and Risk of Nursing Home Placement,” Medical Care, Vol. 41, No. 12, 2003, pp. 1407-1416. doi:10.1097/01.MLR.0000100587.51573.7A

[8] S. McFall and B. H. Miller, "Caregiver Burden and Nursing Home Admission of Frail Elderly Persons,” The Journals of Gerontology, Vol. 47, No. 2, 1992, pp. S73-S79.

[9] C. Eng, et al., "Program of All-Inclusive Care for the Elderly (PACE): An Innovative Model of Integrated Geriatric Care and Financing," Journal of the American Geriatrics Society, Vol. 45, No. 2, 1997, pp. 223-232.

[10] G. Mitchell 2nd, et al., "The Relative Benefits and Cost of Medicaid Home- and Community-Based Services in Florida," The Gerontologist, Vol. 46, No. 4, 2006, pp. 483-494. doi:10.1093/geront/46.4.483

[11] K. F. Ferraro and J. A. Kelley-Moore, "A Half Century of longitudinal Methods in Social Gerontology: Evidence of Change in the Journal," The Journals of Gerontology: Series $B$, Vol. 58, No. 5, 2003, pp. S264-S270. doi:10.1093/geronb/58.5.S264

[12] R. Andersen and J. F. Newman, "Societal and Individual Determinants of Medical Care Utilization in the United States," The Milbank Memorial Fund Quarterly, Health and Society, Vol. 51, No. 1, 1973, pp. 95-124. doi: $10.2307 / 3349613$

[13] R. M. Andersen, “A Behavioral Model of Families' Use of Health Services,” Research Series, University of Chicago, Center for Health administration Studies, Chicago, 1968.

[14] R. M. Andersen, "Revisiting the Behavioral Model and Access to Medical Care: Does It Matter?” Journal of Health and Social Behavior, Vol. 36, No. 1, 1995, pp. 1-10. doi:10.2307/2137284

[15] J. A. Krout, J. Oggins and H. H. Holmes, "Patterns of Service Use in a Continuing Care Retirement Commu- nity," The Gerontologist, Vol. 40, No. 6, 2000, pp. 698-705. doi:10.1093/geront/40.6.698

[16] J. Mitchell and J. A. Krout, "Discretion and Service Use among Older Adults: The Behavioral Model Revisited," The Gerontologist, Vol. 38, No. 2, 1998, pp. 159-168. doi:10.1093/geront/38.2.159

[17] R. Andersen, et al., "Application of the Behavioral Model to Health Studies of Asian and Pacific Islander Americans," Asian American and Pacific Islander Journal of Health, Vol. 3, No. 2, 1995, pp. 128-141.

[18] E. A. Miller and W. G. Weissert, "Predicting Elderly People's Risk for Nursing Home Placement, Hospitalization, Functional Impairment, and Mortality: A Synthesis,” Medical Care Research and Review, Vol. 57, No. 3, 2000, pp. 259-297. doi:10.1177/107755870005700301

[19] C. Mustard, et al., "What Determines the Need for Nursing Home Admission in a Universally Insured Population?” Journal of Health Services Research \& Policy, Vol. 4, No. 4, 1999, pp. 197-203.

[20] M. Tomiak, et al., "Factors Associated with Nursing-Home Entry for Elders in Manitoba, Canada,” The Journals of Gerontology: Series A, Vol. 55, No. 5, 2000 , pp. M279-M287. doi:10.1093/gerona/55.5.M279

[21] D. Lekan-Rutledge, "Functional Assessment," In: M. A. Matteson, E. S. McConnel and A. D. Linton, Ed., Gerontological Nursing: Concepts and Practice, Sounders Company, Philadelphia, 1998.

[22] R. J. Johnson and F. D. Wolinsky, "Use of CommunityBased Long-Term Care Services by Older Adults," Journal of Aging and Health, Vol. 8, No. 4, 1996, pp. 512-537. doi:10.1177/089826439600800403

[23] S. C. Miller, et al., "Time to Nursing Home Admission for Persons with Alzheimer's Disease: The Effect of Health Care System Characteristics,” The Journals of Gerontology: Series B, Vol. 53, No. 6, 1998, pp. S341-S353. doi:10.1093/geronb/53B.6.S341

[24] S. J. Newman, et al., "Overwhelming Odds: Caregiving and the Risk of Institutionalization," The Journals of Gerontology, Vol. 45, No. 5, 1990, pp. S173-S183.

[25] The Second Longitudinal Study of Aging, The Second Supplement on Aging: 1994 (Version 2, No. 1, September 1998); Wave 2 Survivor Data File (Version SF1.2, June 2002); Wave 2 Decedent Data File (Version DF1.1, August 2002); Wave 3 Survivor Data File (Version SF2.1, October 2002); Wave 3 Decedent Data File (Version DF2.1, December 2002) 2002 [cited 2002; Data files]. http://www.cdc.gov/nchs/about/otheract/ aging/lsoa2.htm.

[26] K. G. Jöreskog and D. Sörbom, "LISREL8: Structural Equation Modeling with the SIMPLIS Cammand Language,” Lawrence Erlbaum Associates, Hillsdale, 1993.

[27] P. Kemper, "The Use of Formal and Informal Home Care by the Disabled Elderly," Health Services Research, Vol. 27, No. 4, 1992, pp. 421-451.

[28] V. L. Greene, M. E. Lovely and J. I. Ondrich, “The Cost-Effectiveness of Community Services in a Frail Elderly Population,” The Gerontologist, Vol. 33, No. 2, 1993, pp. 177-189. doi:10.1093/geront/33.2.177 
[29] The Second Longitudinal Study of Aging, The Second Supplement on Aging: Wave 3 Survivor Questionnaire (Version SF2.1, October 2002) 2002 [cited 2002; Coding Book files].

http://www.cdc.gov/nchs/ about/otheract/aging/lsoa2.htm.

[30] Q. Cai, J. W. Salmon and M. E. Rodgers, "Factors Associated with Long-Stay Nursing Home Admissions among the US Elderly Population: Comparison of Logistic Regression and the Cox Proportional Hazards Model with Policy Implications for Social Work," Social Work in Health Care, Vol. 48, No. 2, 2009, pp. 154-168. doi:10.1080/00981380802580588

[31] R. F. Boaz and C. F. Muller, "Predicting the Risk of 'Permanent' Nursing Home Residence: The Role of Community Help as Indicated by Family Helpers and Prior Living Arrangements," Health Services Research, Vol. 29, No. 4, 1994, pp. 391-414.
[32] Y. M. Chen, “A Community-Based Long-Term Care Model for the US Elderly,” Doctoral Dissertation, University of Washington, Seattle, 2004, p. 258.

[33] N. Muramatsu, et al., "Risk of Nursing Home Admission among Older Americans: Does States' Spending on Home- and Community-Based Services Matter?” The Journals of Gerontology: Series B, Vol. 62, No. 3, 2007, pp. S169-S178.

[34] D. J. Rabiner, S. C. Stearns and E. Mutran, “The Effect of Channeling on in-Home Utilization and Subsequent Nursing Home Care: A Simultaneous Equation Perspective,” Health Services Research, Vol. 29, No. 5, 1994, pp. 605622.

[35] M. Kitchener, et al., "Institutional and Community-Based Long-Term Care: A Comparative Estimate of Public Costs,” Journal of Health \& Social Policy, Vol. 22, No. 2, 2006, pp. 31-50. doi:10.1300/J045v22n02_03 